\title{
Capacity to Vote in Persons with Dementia and the Elderly
}

\author{
Luis Javier Irastorza, ${ }^{1}$ Pablo Corujo, ${ }^{2}$ and Pilar Bañuelos ${ }^{2}$ \\ ${ }^{1}$ MHC Arganda, Juan de la Cierva 20, Arganda del Rey, 28500 Madrid, Spain \\ ${ }^{2}$ Residencia de Personas Mayores de Arganda, CAM, Arganda del Rey, 28500 Madrid, Spain
}

Correspondence should be addressed to Luis Javier Irastorza, ljirastorza@telefonica.net

Received 14 November 2010; Revised 15 April 2011; Accepted 7 June 2011

Academic Editor: Vincenzo Solfrizzi

Copyright ( 2011 Luis Javier Irastorza et al. This is an open access article distributed under the Creative Commons Attribution License, which permits unrestricted use, distribution, and reproduction in any medium, provided the original work is properly cited.

The capacity to vote in patients with mental illness is increasingly questioned. The objective of this study is to evaluate this capacity in a group of subjects with dementia (Alzheimer's disease) and other elderly subjects without dementia. With a sample of 68 subjects with dementia and 25 controls living in a senior residence, a transversal study was carried out over 4 months. Subjects were evaluated with the Mini-Mental State Examination (MMSE) and the Competence Assessment Tool for voting (CAT-V). The results were more positive for the Doe criteria (as part of the CAT-V), and a correlation was found with the MMSE in subjects with dementia and, to a lesser degree, in the controls. We conclude that the capacity to vote is related to cognitive deterioration and, within that, is more related to understanding and appreciation.

\section{Introduction}

Voting is a legal right in many countries. But the exercise of this right does not mean that all persons have the capacity to vote. There might be cases of people with the competence to vote, but without the necessary capacity. For this reason, there is increasingly more literature seeking a tool to evaluate the capacity to vote, for patients with dementia as well as other mental disorders, such as those hospitalized with acute symptoms, and so forth [1-4].

In the evaluation of the capacity for the act of voting, there are 6 questions that evaluate the functional abilities of the person, based on the 4 standard decision-making abilities: understanding, choice, reasoning, and appreciation. Some of these questions come from the standard questionnaire of a federal court, related to understanding the nature of voting, understanding its effect and vote selection in Maine, USA (Doe criteria) [5]. In addition, items have been added incorporated in the CAT-V test [2]: comparative reasoning, consequential reasoning, and appreciation.

This instrument has been used in various studies [2-4]. However, doubt persists as to which items to use for screening and to which persons. What should be the cutoff point? Should some items be weighted more than others?
Our study attempts to resolve these questions in two ways: using the MMSE [6] as a cognitive variable and the CAT-V as a voting test in two samples: one group of patients with Alzheimer's dementia living in a senior residence and a second group of persons living in the same residence who suffer no mental illness.

\section{Materials and Methods}

2.1. Participants. The study included 68 patients residing in the Arganda del Rey Senior Residence, diagnosed with Alzheimer's dementia (according to DSM-IV-TR criteria) [7] and 25 subjects living in the same residence, but with a MMSE score greater than 24 and no mental illness, who participated on a voluntary basis. The severity of dementia was evaluated using the standard cut-off points in the MiniMental State Examination (MMSE): Mild, 20 to 23; moderate, 12 to 19; severe, <12 [6]. Subjects were evaluated over a 4-month period, from August to November 2010. They were recruited randomly, given the high percentage of patients with various types of dementia living in this residence. All spoke Spanish.

As a control group, 25 additional subjects were evaluated with the same criteria and lived in the same residence, 
TABle 1: Characteristics of 68 patients with Alzheimer's dementia and 25 elderly subjects without mental illness of the Arganda Senior Residence who were evaluated for their capacity to vote.

\begin{tabular}{|c|c|c|c|c|}
\hline \multirow[b]{2}{*}{ Characteristics } & \multicolumn{2}{|c|}{ Dementia group } & \multicolumn{2}{|c|}{ Normal group } \\
\hline & $N$ & $\%$ or range & $N$ & $\%$ or range \\
\hline \multicolumn{5}{|l|}{ Sex } \\
\hline Male & 16 & 23.5 & 9 & 36 \\
\hline Female & 52 & 76.5 & 16 & 64 \\
\hline \multicolumn{5}{|l|}{ Age } \\
\hline $70-79$ & 10 & 14.7 & 4 & 16 \\
\hline $80-89$ & 35 & 51.5 & 16 & 64 \\
\hline $90-99$ & 22 & 32.4 & 5 & 20 \\
\hline Age $(M \pm S D)$ & $86.4 \pm 7$ & $61-99$ & $84.5 \pm 6.6$ & $70-98$ \\
\hline MMSE score $(\mathrm{M} \pm \mathrm{SD})^{\mathrm{a}}$ & $12.7 \pm 6.3$ & $0-22$ & $26.8 \pm 1.6$ & $25-29$ \\
\hline
\end{tabular}

${ }^{a}$ Possible scoring for MMSE ranges from 0 to 30, with higher score representing greater cognitive capacity.

but were not diagnosed with any type of dementia or any other mental illness (according to DSM-IV-TR) which could confound the results of the study.

2.2. Evaluation Instruments. We used the CAT-V to evaluate the capacity to vote. The questions used were adapted from the criteria for decision making: understanding, choice, reasoning, and appreciation. As previously stated, these are the Doe criteria: the voting capacity is applied according to whether the subject understands the nature and effect of the vote, the choice of candidate [2]. Besides, comparative and consequential reasoning (comparatively reasons about the candidates and reasons the consequences for the voter) and appreciation of the vote (appreciates the vote weighing what candidate is chosen and who would be chosen in the next election) are added to these Doe criteria in formulating the CAT-V. The scoring of this is 2 if the performance was adequate; 1 if the performance was ordinary or doubtful; 0 if the subject is not capable of considering or answering the question.

Although our study did not look at interexaminer reliability, we took into account the experience in another work completed by the same authors [3], with the same tools. After various training sessions on the test (CAT-V), we tried to adapt it to the Spanish voting system: here we do not choose between one candidate and another, as in the USA, but among various political parties. Information was given to the participants about which political party would be chosen, not which candidate.

In addition, we used the MMSE [6] to evaluate cognitive capacity, with the aforementioned scoring for severity of dementia.

The DSM-IV-TR classification criteria were used to diagnose Alzheimer's dementia and to exclude possible clinical cases in the group of control patients without dementia.

2.3. Data Analysis. Scores were given for the Doe criteria for each participant, as a result of adding the points for understanding of nature and effect of the vote, of 0 to 4 points, plus two for vote choice. In addition, we considered the scoring for reasoning, of 0 to 2 points for comparative and another
0 to 2 for consequential. Appreciation was also scored on a scale of 0 to 2 .

We used in the comparison of the means of the two groups the Student's $t$-test (normal distribution) and the Mann-Whitney $U$ test (abnormal distribution). In order to measure the association between qualitative variables, the Chi-square and Fisher exact tests were used.

The Spearman correlation coefficient and the KruskalWallis Chi-square tests were used to look at the associations between the CAT-V measurements, and with respect to the MMSE scoring and sociodemographic characteristics.

2.4. Human Subject Protections. All participants or their caregivers gave verbal informed consent to participate in the study. They were assured that the information they gave would be used solely for the purposes of this study and they did not display apprehension in this regard.

\section{Results}

3.1. Characteristics of the Subjects. Sixty-eight (68) patients with dementia and 25 elderly subjects without mental illness completed the study. Table 1 shows their demographic and clinical characteristics. According to the MMSE, there were 27 patients with severe dementia (39.7\%), 33 with moderate dementia (48.5\%), and 8 with mild dementia (11.8\%) in the group of patients with dementia. There were no significant differences in age or sex among the two groups, and as expected, there were differences in MMSE $(F=29.4 ; d f=$ 91; $P<0.0001)$.

3.2. Development of the CAT-V and Its Subscales. Table 2 shows the CAT-V scoring of the study participants. It appears that, from the sample of those with dementia, about half understood the nature and effect of the vote; this was not the case for the choice itself, in which $75 \%$ failed. Forty percent (40\%) obtained a 0 in total Doe criteria. The result is also negative for reasoning, particularly comparative reasoning (0 score in 82\%). In appreciation, however, more than 65\% achieved good scores. 
TABLE 2: Scoring of the capacity to vote (CAT-Va competency assessment tool for voting) of 68 patients with dementia and 25 controls (elderly without dementia).

\begin{tabular}{|c|c|c|c|c|}
\hline \multirow[b]{2}{*}{ Item and score ${ }^{b}$} & \multicolumn{2}{|c|}{ Alzheimer's } & \multicolumn{2}{|c|}{ Elderly } \\
\hline & $N$ & $\%$ & $N$ & $\%$ \\
\hline \multicolumn{5}{|l|}{ Doe criteria $^{\mathrm{c}}$} \\
\hline \multicolumn{5}{|c|}{ Understanding nature of the vote } \\
\hline 2 & 18 & 26.5 & 24 & 96 \\
\hline 1 & 18 & 26.5 & 1 & 4 \\
\hline 0 & 32 & 46.1 & 0 & - \\
\hline \multicolumn{5}{|c|}{ Understanding effect of the vote } \\
\hline 2 & 6 & 8.8 & 18 & 72 \\
\hline 1 & 24 & 35.3 & 7 & 28 \\
\hline 0 & 38 & 55.9 & 0 & - \\
\hline \multicolumn{5}{|l|}{ Vote choice } \\
\hline 2 & 1 & 1.5 & 8 & 32 \\
\hline 1 & 16 & 23.5 & 17 & 68 \\
\hline 0 & 51 & 75 & 0 & - \\
\hline \multicolumn{5}{|l|}{ Total Doe score } \\
\hline 6 & 0 & - & 7 & 28 \\
\hline 5 & 3 & 4.4 & 12 & 48 \\
\hline 4 & 8 & 11.8 & 5 & 20 \\
\hline 3 & 11 & 16.2 & 1 & 4 \\
\hline 2 & 9 & 13.2 & 0 & - \\
\hline 1 & 10 & 14.7 & 0 & - \\
\hline 0 & 27 & 39.7 & 0 & - \\
\hline \multicolumn{5}{|l|}{ Additional items ${ }^{\mathrm{a}}$} \\
\hline \multicolumn{5}{|c|}{ Comparative reasoning } \\
\hline 2 & 0 & - & 7 & 28 \\
\hline 1 & 12 & 17.6 & 18 & 72 \\
\hline 0 & 56 & 82.4 & 0 & - \\
\hline \multicolumn{5}{|c|}{ Consequential reasoning } \\
\hline 2 & 1 & 1.5 & 14 & 56 \\
\hline 1 & 23 & 33.8 & 11 & 44 \\
\hline 0 & 44 & 64.7 & 0 & - \\
\hline \multicolumn{5}{|l|}{ Appreciation } \\
\hline 2 & 13 & 19.1 & 21 & 84 \\
\hline 1 & 32 & 47.1 & 4 & 16 \\
\hline 0 & 23 & 33.8 & 0 & - \\
\hline
\end{tabular}

${ }^{a}$ CAT-V.: test to evaluate the capacity to vote, created by Appelbaum et al., 2005 [2].

${ }^{b}$ Descending order.

${ }^{\mathrm{c}}$ According to Doe versus Rowe criteria for competence to vote of 2001 [5].

When we compare the CAT-V items in the two groups, we observe significant differences: in understanding the nature of the vote (Chi-square, $\chi^{2}=35.9 ; d f=2 ; P<$ $0.0001)$, understanding the effect of the vote $\left(\chi^{2}=42.5 ; d f=\right.$ 2; $P<0.0001)$, vote choice $\left(\chi^{2}=46.5 ; d f=2 ; P<0.0001\right)$, comparative reasoning $\left(\chi^{2}=56.4 ; d f=2 ; P<0.0001\right)$, consequential reasoning $\left(\chi^{2}=50.4 ; d f=2 ; P<0.0001\right)$, and appreciation $\left(\chi^{2}=34.1 ; d f=2 ; P<0.0001\right)$.

3.3. Relationship between CAT-V Scores and Severity of Dementia and Normal Elderly and other Variables. In the group of patients with dementia, there is a correlation between the MMSE and the Doe criteria: $r_{s}=0.833, N=$ $68, P<0.0001$. High scores on the Doe questions are associated with better development in MMSE (Figure 1). The figure shows that all subjects with severe dementia (MMSE < 12) scored 1 or less on the Doe questions and all those with mild dementia (except for one case that scored 1) scored 3 or higher on the Doe score. But those with moderate dementia had the greatest variability in the Doe, from 0 to 4 .

In the same group of patients with dementia, the correlation of MMSE and the CAT-V reasoning items is $r_{s}=0.635$, $N=68, P<0$. 0001, bilateral sig.; high scores in MMSE with greater reasoning development $\left(r_{s}=0.61, N=68, P<\right.$ 0.0001 ); except for one exception, all those who scored 2 have 16 or more on MMSE. However, there are cases with mild and moderate dementia that vary between 0 and 2 on the reasoning criteria. 


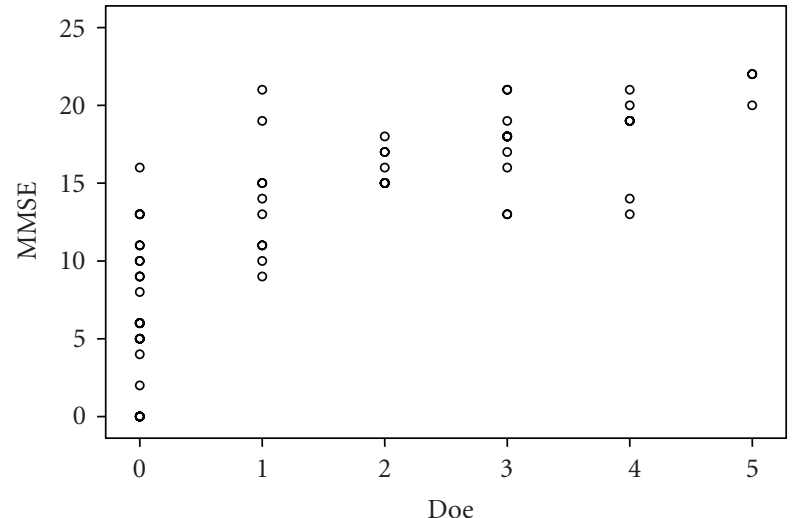

Figure 1: Relation of Mini-Mental State Examination scores to Doe criteria in 68 patients with Alzheimer's disease.

In dementia's group, the correlation between MMSE and appreciation is Kruskal-Wallis test, $\chi^{2}=39.6 ; d f=2 ; P<$ 0.0001. All patients with the maximum of 2 in appreciation obtain a minimum of 15 on the MMSE. Here, moderate dementia varies between 0 and 2 and mild between 1 and 2 .

Spearman correlations between MMSE and CAT-V items are as follows.

(1) With nature of vote: $r_{s}=0.744, P<0.0001$. With effect of vote: $r_{s}=0.738, P<0.001$.

(2) Correlation between MMSE and the Doe item of vote choice continues to be significant $\left(r_{s}=0.478\right.$, $P<0.0001)$, with high scores in MMSE and in vote choice. However, scoring of moderate dementia varied a great deal (from 0 to 21 ).

(3) With comparative reasoning: $r_{s}=0.392, P<0.001$. With consequential reasoning: $r_{s}=0.553, P<$ 0.0001 .

There is a correlation between age, in the oldest range (90 to 99), and the Doe criteria (Kruskal-Wallis, $\chi^{2}=12.86$, $d f=6, P=0.045$ ); the majority, save exceptions, of patients in this age group achieve scores of 3 or less in these criteria. In all other age ranges, as with sex, there are no significant associations.

When we compared the patients with dementia with the controls, elderly without dementia, we observed significant differences with the Mann-Whitney $U$ statistic in the three Doe criteria together $(U=69.5, P<0.0001)$, the reasoning items $(U=35.5, P<0.0001)$, and appreciation item $(U=$ 252.5, $P<0.0001)$, affecting all CAT-V criteria $(U=29$, $P<0.0001)$.

Correlation between MMSE and Doe criteria is shown in Figures 2, 3, and 4 (two groups together, dementia and elderly groups).

\section{Discussion}

We believe that this is the first study comparing the capacity to vote in patients with Alzheimer's dementia and in elderly

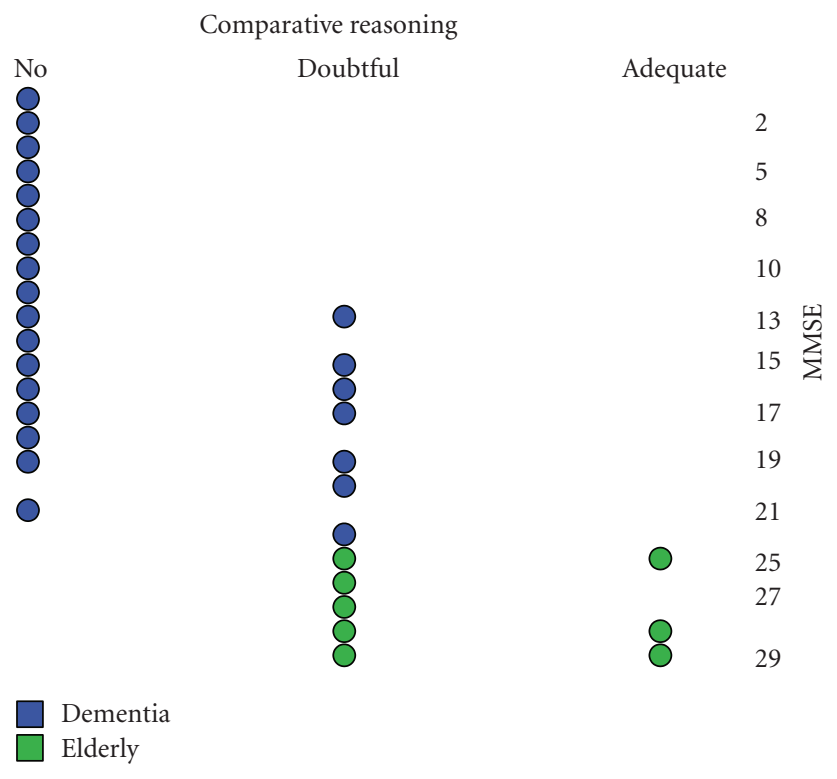

Figure 2: Relation of Mini-Mental State Examination Scores to scores on comparative reasoning for 68 patients with Alzheimer's disease and 25 controls.

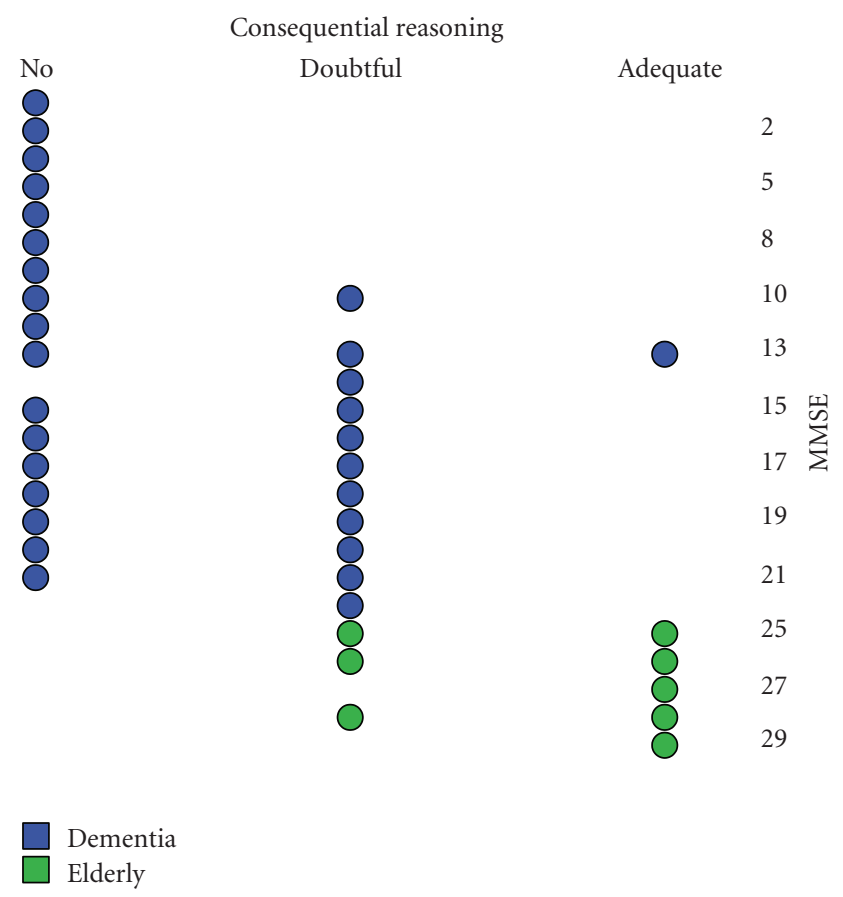

Figure 3: Relation of Mini-Mental State Examination Scores to scores on consequential reasoning for 68 patients with Alzheimer's disease and 25 controls.

subjects without dementia or any other mental illness, using CAT-V.

We observe that patients with dementia understand the nature and effect of the vote (53\% and $44 \%$, resp.), and appreciate its consequences $(66.2 \%)$ but do not do as well when it is time to make a voting choice (25\%) and to 


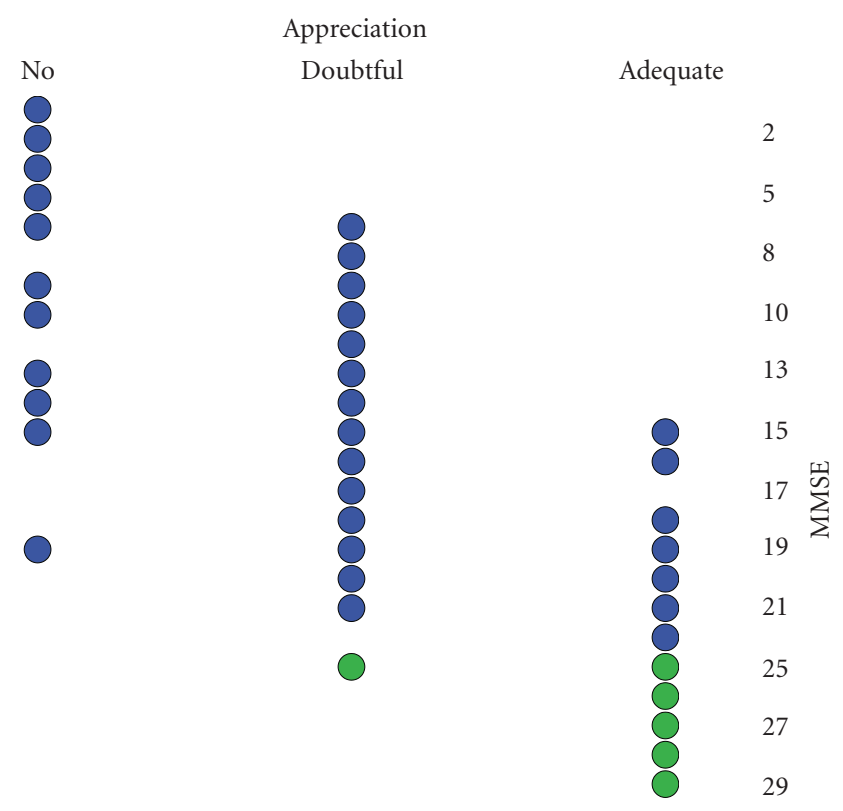

Dementia

Elderly

Figure 4: Relation of Mini-Mental State Examination Scores to scores on appreciation for 68 patients with Alzheimer's disease and 25 controls.

consequential reasoning (35.3\%). There is a correlation among all the items with MMSE, that is, the lower the score, the lower the capacity to vote, and those with mild dementia usually retain the capacity to vote. We agree with another study that also used CAT-V and MMSE in patients with dementia, but with less cognitive deterioration [2]. Other authors have not found a correlation between the capacity to vote and reasoning [3] or with clinical (psychosis, bipolar disorders) and cognitive variables [4]. Within this several mental disorder study, the authors verify that patients correctly understand and reason their vote and appreciate its associated consequences, like in our elderly control group. We observe that Doe scores are lower in the Applebaum study [2], although we agree in the same tendencies of variability in moderate dementia.

Almost all patients with mild dementia had Doe scores greater than or equal to 2 . We do not agree with the Raad et al. study [4], with an MMSE higher than in our study, that did not find correlation between high MMSE scores and Doe criteria for voting. This could indicate that dementias are more likely to affect the capacity to vote associated with cognitive deterioration, and less so in other mental disorders.

There are significant differences in scoring of the MMSE and CAT-V between both groups, as would be expected. This could be understood that the patients without mental illness, although they are elderly, and without cognitive deterioration, have a greater capacity to vote. Therefore, in this group, the MMSE does not serve as a predictor test and it does in patients with moderate dementia. As observed by Pruchno et al. [8], cognitive screening serves to suggest when a complete evaluation of capacity is necessary but is not informative about the specific deficits of capacity. One cognitive screening test is the MMSE, which correlates, as we have seen, with capacity tools, but is not very sensitive or specific $[9,10]$.

The MMSE has been used to evaluate consent for treatment, with similar results $[11,12]$, or in relation to the loss of autonomy, lack of judgment and capacity to make decisions $[13,14]$. But, in other papers, evaluation of the capacity to vote has not been reliable $[15,16]$. In our study, we also were unable to obtain a reliable cut-off: it is valid for severe dementia, but not as much for mild dementia and even less so for moderate dementia, nor has MMSE correlated with different mental disorders (schizophrenia, mood disorders) or intellectual coefficient [4].

It seems that if we place a high threshold on the voting test, including the reasoning and appreciation items, various subjects remain outside that threshold although they do have the capacity to vote according to the Doe criteria. And if we focus on these, the vote choice item also presents difficulties [4]. We see that it is complicated that some subjects make a good voting choice, as in our study. If we try to interpret this, we can find other influential factors, such as the subjects' access to information, proximity to the elections, and cultural level.

There are studies that show that patients with mild and moderate dementia have a normal score in the subscales of appreciation and reasoning (in the MacArthur Clinical Research test) [17]. This test, which evaluates competency, has been questioned for showing deterioration, and the patient was capable of making decisions about treatment. We also observe cases of normal consequential reasoning and appreciation in moderate dementia.

The voting test we used, the CAT-V, does correlate with the MMSE in Alzheimer's dementias, both in our study as in those of other authors [2, 3]. We advocate its use but with some clarifications: strengthen the vote choice item with more information. This may be in contradiction with possible voting fraud or misapplication if we focus on imminent elections. But, at the time of the study, we observe that many of the patients made mistakes. Reasoning and, to a lesser degree, appreciation are also questionable variables depending on the severity of the dementia. Thus, we could not define a cutoff point in the CAT-V in relation to these items, particularly in those with moderate dementia and in subjects who want to vote. This last factor, not examined in our study, also does not correlate with the MMSE [18].

Nor do we know the cut-off point of the test if we score more for appreciation than for reasoning. In our study, the subjects perform better in terms of appreciation of the consequences of an election, the absence of false beliefs that direct own appreciation [19]. They also obtained better results on consequential reasoning.

This study has several limitations: not having performed an interexaminer reliability test and the small sample size. The first is addressed in part due to the authors' knowledge of the test from other studies [3]. Patient daily activity evaluation (ADL and IADL) was not used, either, searching cognitive deterioration more than functional one. 
Understanding is related to memory, executive capacities and name comparison in dementia [20]. Appreciation is less associated with neurophysiological tests. Reasoning is related in dementia to working memory and executive functions [3].

Future studies should look at the factor analysis of the MMSE items that correlate with the CAT-V, with ADL, and IADL and with other sociodemographic variables.

\section{Conclusions}

It is important to carry out an evaluation of the capacity to vote on patients with moderate dementia. The MMSE and the CAT-V test can be useful to this end. The criteria of understanding and appreciation are easier for the patients, but not those of vote choice and reasoning. Cognitive deterioration, but not age, influences the capacity to vote.

\section{Authors' Contribution}

All authors contributed to the design of the study. P. Corujo and P. Bañuelos identified the participants, did the individual interviews and administered the neuropsychological scales. L. J. Irastorza contributed to the analysis and interpretation of data, drafted the article and revised.

\section{Conflict of Interests}

All authors declare that they have no financial interest that may be relevant to the submitted work; only we received help for translation of the text by S. A. Andromaco-Grunnenthal.

\section{References}

[1] J. H. T. Karlawish and C. M. Clark, "Diagnostic evaluation of elderly patients with mild memory problems," Annals of Internal Medicine, vol. 138, no. 5, pp. 411-419, 2003.

[2] P. S. Appelbaum, R. J. Bonnie, and J. H. Karlawish, "The capacity to vote of persons with Alzheimer's disease," American Journal of Psychiatry, vol. 162, no. 11, pp. 2094-2100, 2005.

[3] L. J. Irastorza, P. Corujo, and P. Bañuelos, "The competence to vote in patients with dementia," Revista de Neurologia, vol. 44, no. 6, pp. 321-325, 2007.

[4] R. Raad, J. Karlawish, and P. S. Appelbaum, "The capacity to vote of persons with serious mental illness," Psychiatric Services, vol. 60, no. 5, pp. 624-628, 2009.

[5] Doe v Rowe, 156 F, supplement 2d 35(DMe), 2001.

[6] M. F. Folstein, S. E. Folstein, and P. R. McHugh, "Mini-mental state": a practical method for grading the cognitive state of patients for the clinician," Journal of Psychiatric Research, vol. 12, no. 3, pp. 189-198, 1975.

[7] DMS-IV-TR, Manual Diagnostico y Estadístico de los Trastornos Mentales, Masson, Barcelona, Spain, Texto Revisado edition, 2002.

[8] R. A. Pruchno, M. A. Smyer, M. S. Rose, P. E. Hartman-Stein, and D. L. Henderson-Laribee, "Competence of long-term care residents to participate in decisions about their medical care: a brief, objective assessment," Gerontologist, vol. 35, no. 5, pp. 622-629, 1995.

[9] L. J. Fitten, R. Lusky, and C. Hamann, "Assessing treatment decision-making capacity in elderly nursing home residents,"
Journal of the American Geriatrics Society, vol. 38, no. 10, pp. 1097-1104, 1990.

[10] S. Y. H. Kim and E. D. Caine, "Utility and limits of the mini mental state examination in evaluating consent capacity in Alzheimer's disease," Psychiatric Services, vol. 53, no. 10, pp. 1322-1324, 2002.

[11] V. Raymont, P. W. Bingley, A. Buchanan et al., "Prevalence of mental incapacity in medical inpatients and associated risk factors: cross-sectional study," The Lancet, vol. 364, no. 9443, pp. 1421-1427, 2004.

[12] E. Etchells, P. Darzins, M. Silberfeld et al., "Assessment of patient capacity to consent to treatment," Journal of General Internal Medicine, vol. 14, no. 1, pp. 27-34, 1999.

[13] J. S. Huthwaite, R. C. Martin, H. R. Griffith, B. Anderson, L. E. Harrell, and D. C. Marson, "Declining medical decisionmaking capacity in mild AD: a two-year longitudinal study," Behavioral Sciences and the Law, vol. 24, no. 4, pp. 453-463, 2006.

[14] J. Karlawish, "Measuring decision-making capacity in cognitively impaired individuals," Neurosignals, vol. 16, no. 1, pp. 91-98, 2008.

[15] J. Karlawish, "Voting by older adults with cognitive impairments," LDI Issue Brief, vol. 13, no. 4, pp. 1-4, 2008.

[16] A. Blais, L. Massicotte, and A. Yoshinaka, "Deciding who has the right to vote: a comparative analysis of election laws," Electoral Studies, vol. 20, no. 1, pp. 41-62, 2001.

[17] S. Y. H. Kim, E. D. Caine, G. W. Currier, A. Leibovici, and J. M. Ryan, "Assessing the competence of persons with Alzheimer's disease in providing informed consent for participation in research," American Journal of Psychiatry, vol. 158, no. 5, pp. 712-717, 2001.

[18] A. Bosquet, A. Medjkane, D. Voitel-Warneke, P. Vinceneux, and I. Mahé, "The vote of acute medical inpatients: a prospective study," Journal of Aging and Health, vol. 21, no. 5, pp. 699712, 2009.

[19] E. R. Saks, L. B. Dunn, B. J. Marshall, G. V. Nayak, S. Golshan, and D. V. Jeste, "The California scale of appreciation: a new instrument to measure the appreciation component of capacity to consent to research," American Journal of Geriatric Psychiatry, vol. 10, no. 2, pp. 166-174, 2002.

[20] M. P. Dymek, P. Atchison, L. Harrell, and D. C. Marson, "Competency to consent to medical treatment in cognitively impaired patients with Parkinson's disease," Neurology, vol. 56, no. 1, pp. 17-24, 2001. 


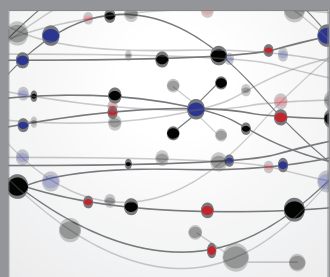

The Scientific World Journal
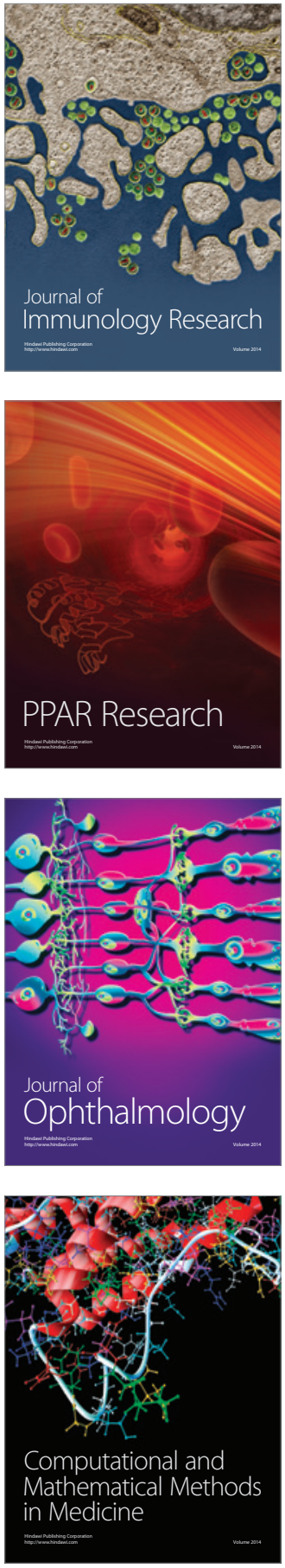

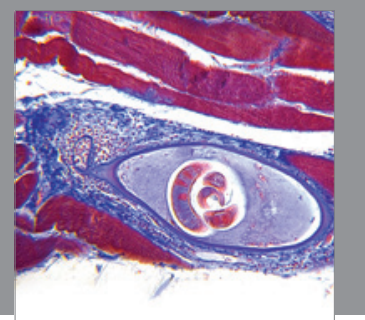

Gastroenterology

Research and Practice
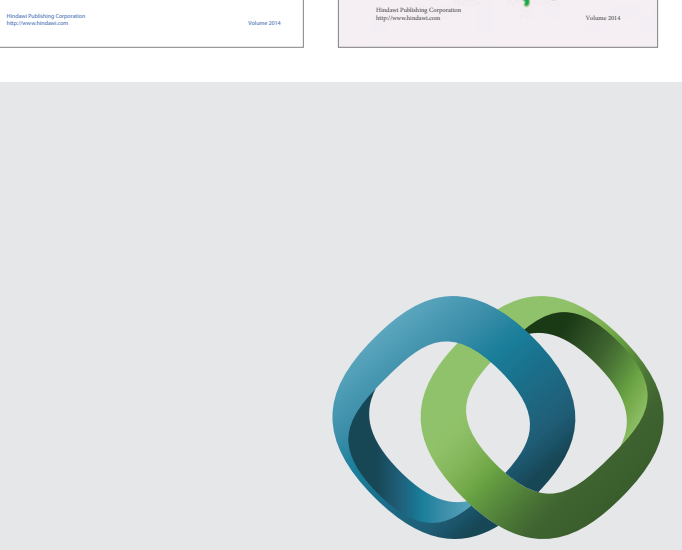

\section{Hindawi}

Submit your manuscripts at

http://www.hindawi.com
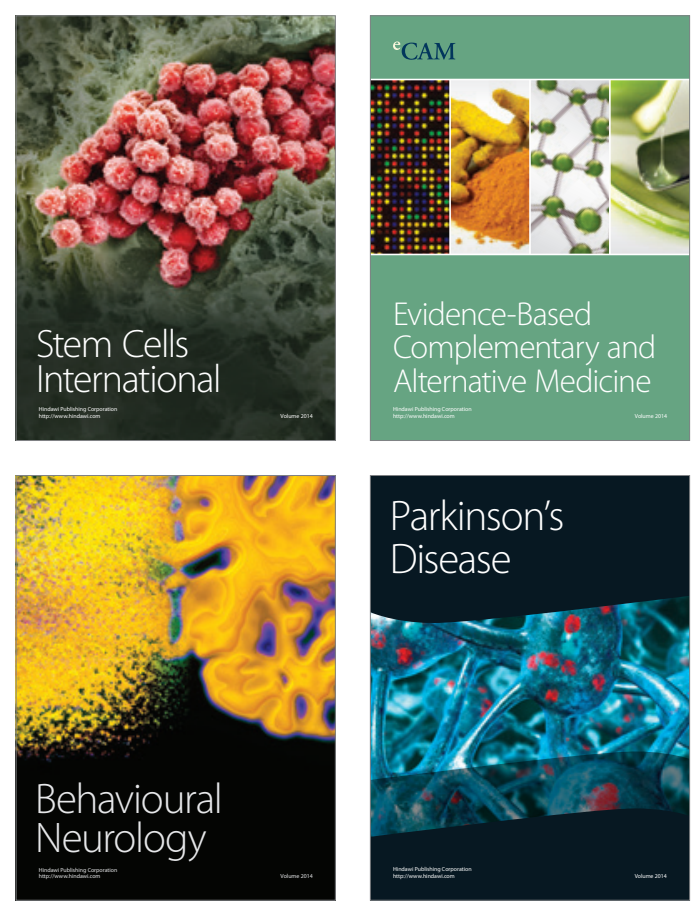

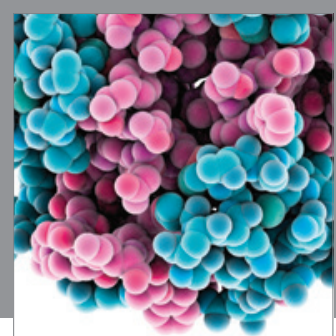

Journal of
Diabetes Research

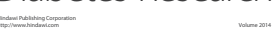

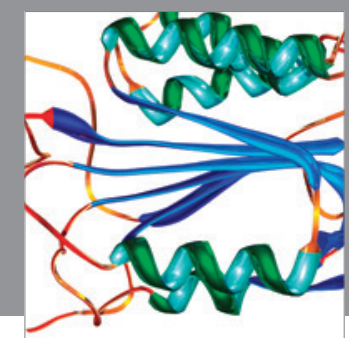

Disease Markers
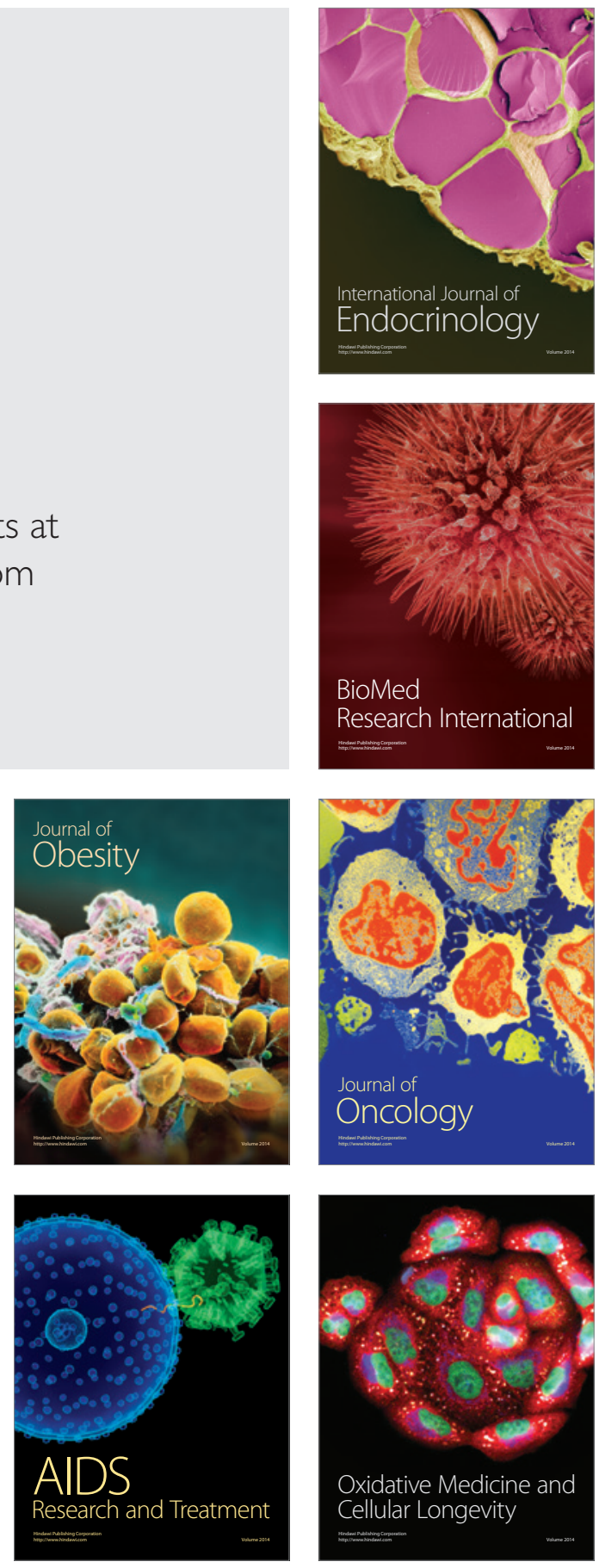